\section{BRAZIULIAN JOURNAL \\ OF MEDICAL AND BIOLOGICAL RESEARCH}

www.bjournal.com.br
ISSN 1414-431X

Volume 45 (12) 1102-1340 December 2012

\section{BIOMIDICAL SCIENCES}

AND

CLINICAL INVESTIGATION

Braz J Med Biol Res, December 2012, Volume 45(12) 1248-1254

doi: 10.1590/S0100-879X2012007500169

Effects of short-term administration of estradiol on reperfusion arrhythmias in rats of different ages

S.Q. Savergnini, A.M. Reis, R.A.S. Santos, P.E.B. Santos, A.J. Ferreira and A.P. Almeida

The Brazilian Journal of Medical and Biological Research is partially financed by

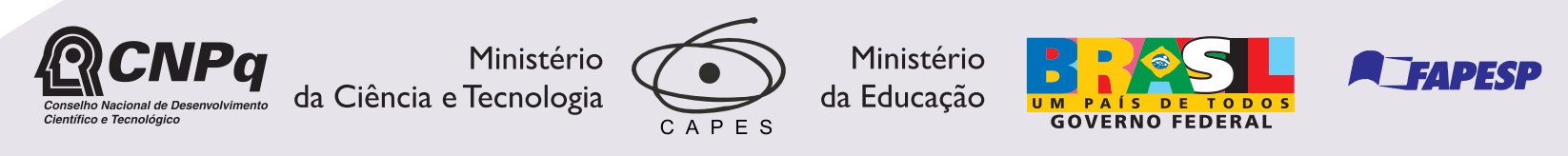

Scied
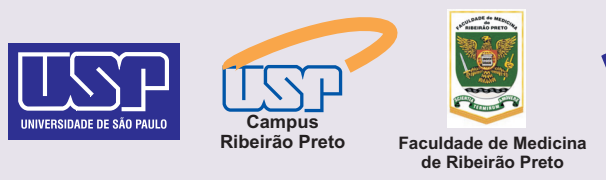

Institutional Sponsors

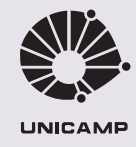

SHIMADZu

$\oplus$

UNICAMP

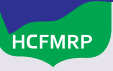

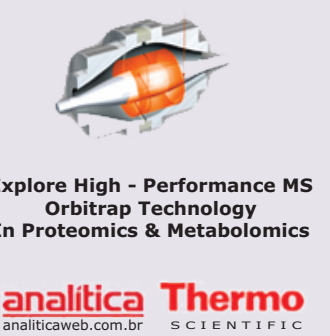




\title{
Effects of short-term administration of estradiol on reperfusion arrhythmias in rats of different ages
}

\author{
S.Q. Savergnini ${ }^{1}$, A.M. Reis ${ }^{1}$, R.A.S. Santos ${ }^{1}$, P.E.B. Santos ${ }^{2 \dagger}$, \\ A.J. Ferreira ${ }^{3}$ and A.P. Almeida ${ }^{1}$ \\ ${ }^{1}$ Departamento de Fisiologia e Biofísica, Instituto de Ciências Biológicas, \\ Universidade Federal de Minas Gerais, Belo Horizonte, MG, Brasil \\ 2Departamento de Farmacologia, Instituto de Ciências Biológicas, \\ Universidade Federal de Minas Gerais, Belo Horizonte, MG, Brasil \\ ${ }^{3}$ Departamento de Morfologia, Instituto de Ciências Biológicas, \\ Universidade Federal de Minas Gerais, Belo Horizonte, MG, Brasil
}

\begin{abstract}
Little is known about age-related differences in short-term effects of estradiol on ischemia-reperfusion (I/R) insults. The present study was designed to evaluate the effects of short-term treatment with estradiol on reperfusion arrhythmias in isolated hearts of 6-7-week-old and 12-14-month-old female rats. Wistar rats were sham-operated, ovariectomized and treated with vehicle or ovariectomized and treated with $17 \beta$-estradiol $\left(E_{2} ; 5 \mu \mathrm{g} \cdot 100 \mathrm{~g}^{-1} \cdot\right.$ day $\left.^{-1}\right)$ for 4 days. Hearts were perfused by the Langendorff technique. Reperfusion arrhythmias, i.e., ventricular tachycardia and/or ventricular fibrillation, were induced by $15 \mathrm{~min}$ of left coronary artery ligation and $30 \mathrm{~min}$ of reperfusion. The duration and incidence of I/R arrhythmias were significantly higher in young rats compared to middle-aged rats (arrhythmia severity index: $9.4 \pm 1.0$ vs $3.0 \pm 0.3$ arbitrary units, respectively, $P<$ 0.05). In addition, middle-aged rats showed lower heart rate, systolic tension and coronary flow. Four-day $\mathrm{E}_{2}$ treatment caused an increase in uterine weight. Although $\mathrm{E}_{2}$ administration had no significant effect on the duration of I/R arrhythmias in middleaged rats, it induced a marked reduction in the rhythm disturbances of young rats accompanied by a decrease in heart rate of isolated hearts. Also, this reduction was associated with an increase in QT interval. No significant changes were observed in the QT interval of middle-aged $\mathrm{E}_{2}$-treated rats. These data demonstrate that short-term estradiol treatment protects against $\mathrm{I} / \mathrm{R}$ arrhythmias in hearts of young female rats. The anti-arrhythmogenic effect of estradiol might be related to a lengthening of the QT interval.
\end{abstract}

Key words: Cardioprotection; Estrogen; Ischemia/reperfusion; Langendorff technique; QT interval

\section{Introduction}

Premenopausal women are less susceptible to heart diseases and sudden cardiac death than men at a similar age (1). The incidence of coronary diseases in women increases substantially after menopause (2). Animal models of heart diseases clearly support the cardioprotective effects of estrogen supplementation. Basic experiments have revealed that estrogen could attenuate ischemia- or reperfusion-induced ventricular arrhythmias, thereby suggesting that sex hormones may have protective effects against cardiac arrhythmias (3). Patten et al. (4) showed that ovariectomized rats supplemented with $17 \beta$-estradiol
$\left(E_{2}\right)$ presented reduced cardiomyocyte apoptosis in vitro and in vivo. Additionally, $\mathrm{E}_{2}$ had an antiarrhythmic activity and reduced the L-type calcium current $\left(\mathrm{I}_{\mathrm{CaL}}\right)$ in female and male rats; however, approximately 10 -fold less hormone was required to produce these effects in female rats (5). The natural cardioprotection observed in female rats is absent after ovariectomy (OVX) and $\mathrm{E}_{2}$ supplementation of estrogen-deficient animals provides protection of myocardial function against ischemia/reperfusion (I/R) injury by decreasing inflammation and apoptotic signaling (6).

Although the effects of chronic administration of estro-

Correspondence: A.J. Ferreira, Departamento de Morfologia, ICB, UFMG, Av. Antônio Carlos, 6627, 31270-901 Belo Horizonte, MG, Brasil. Fax: +55-31-3409-2810. E-mail: anderson@icb.ufmg.br

†'n memoriam

Received March 2, 2012. Accepted August 22, 2012. Available online November 1, 2012. Published December 17, 2012. 
gen have been widely explored in the last few decades, especially in studies involving postmenopausal hormone replacement therapy (7-11), the short-term actions of estrogen have not been fully evaluated. In spite of this, short-term estrogen therapy might be an important strategy to treat cardiovascular diseases. Indeed, short-term administration of $E_{2}$ to ovariectomized spontaneously hypertensive rats (SHR) causes a significant reduction in blood pressure on the fourth day of treatment (12), suggesting that the beneficial effects of $E_{2}$ on the cardiovascular system can be already observed after a few days of hormonal supplement. Thus, the aim of the present study was to investigate the effects of short-term estrogen administration on cardiac reperfusion arrhythmias in young and middle-aged rats since age-related differences might change the cardiovascular responses to the administration of $\mathrm{E}_{2}$.

\section{Material and Methods}

\section{Ethical approval}

All experimental protocols were performed in accordance with the guidelines for the humane use of laboratory animals of our Institute and approved by the local authority, the Ethics Committee in Animal Experimentation (CETEA), protocol \#017/07.

\section{Animals}

Female Wistar rats [6-7 weeks old, $200-250 \mathrm{~g}$ (young, N $=28$ ) and 12-14 months old, 350-400 g (middle-aged, $\mathrm{N}=$ 29)] were obtained from the animal facility of the Instituto de Ciências Biológicas, Universidade Federal de Minas Gerais (CEBIO-UFMG). The animals were housed in a temperature- and humidity-controlled room maintained on a 14:10-h light-dark cycle with free access to food and water.

\section{Surgical ovariectomy}

Rats underwent surgical ovariectomy by standard procedures. Briefly, each ovary was removed and the animals were allowed to recover from the surgery for 18 days before experimentation. Successful OVX was confirmed by a reduction in the uterine weight, which was expressed by the ratio between uterine weight $(\mathrm{mg})$ and body weight $(\mathrm{g})$. Control animals (control group: young, $N=10$, middle-aged, $N=12$ ) were left with intact ovaries. OVX rats received daily injections of $E_{2}$ ( $E_{2}$ group: $5 \mu \mathrm{g} \cdot 100 \mathrm{~g} \mathrm{~g}^{-1}$.day ${ }^{-1}$, SARSA, Hoechst Marion Roussel, France; young, $\mathrm{N}=11$, middle-aged, $\mathrm{N}=$ 7) or vehicle (vehicle group: $0.1 \mathrm{~mL}$ corn oil. $100 \mathrm{~g}^{-1}$. day ${ }^{-1}$; young, $N=7$, middle-aged, $N=10$ ) for 4 days. We chose the dose and duration of treatment with $\mathrm{E}_{2}$ (4 days) based on a previous study by Belo et al. (12). In the cited study, the authors showed that short-term $E_{2}$ treatment $\left(5 \mu \mathrm{g} \cdot 100 \mathrm{~g}^{-1} \cdot\right.$ day $^{-1}$ for 4 days) reduced the arterial pressure of ovariectomized animals. Also, this effect was correlated with an increase in plasma atrial natriuretic peptide levels (12). Thus, these results suggest that only 4 days of administration of $E_{2}$ can induce beneficial cardiovascular effects in female rats.

\section{Isolated heart preparation}

After a 4-day period of treatment, the rats were decapitated 10 to 15 min after intraperitoneal injection of 400 IU heparin. The thorax was immediately opened and the heart was carefully dissected and perfused with Krebs-Ringer solution (118.4 mM NaCl, $4.7 \mathrm{mM} \mathrm{KCl}, 1.2 \mathrm{mM} \mathrm{KH}_{2} \mathrm{PO}_{4}, 1.2 \mathrm{mM}$ $\mathrm{MgSO}_{4} .7 \mathrm{H}_{2} \mathrm{O}, 2.5 \mathrm{mM} \mathrm{CaCl} 2.2 \mathrm{H}_{2} \mathrm{O}, 11.7 \mathrm{mM}$ glucose, and $26.5 \mathrm{mM} \mathrm{NaHCO}_{3}$ ) through a $1.0 \pm 0.3-\mathrm{cm}$ aortic stump. The perfusion fluid was maintained at $37 \pm 1^{\circ} \mathrm{C}$ with a constant pressure of $65 \mathrm{mmHg}$ and constant oxygenation $\left(5 \% \mathrm{CO}_{2}-95 \%\right.$ $\mathrm{O}_{2}$ ). A force transducer was attached through a heart clip to the apex of the ventricles to record the contractile force (tension, $g$ ) in a computer equipped with a data-acquisition system (Biopac System, USA). A diastolic tension of $1.0 \pm 0.2 \mathrm{~g}$ was applied to the hearts. Electrical activity was recorded with an electrocardiogram (Nihon Kohden, Japan) with the aid of 2 cotton wicks placed directly on the surface of the right atrium and left ventricle. Coronary flow was measured by collecting the perfusate over a period of $1 \mathrm{~min}$ at regular intervals. The systolic tension and coronary flow parameters were normalized to the heart mass. Because a diastolic tension of $1.0 \pm 0.2 \mathrm{~g}$ was applied to the hearts, diastolic tension was not normalized to heart mass. After the equilibration period (approximately 30 $\mathrm{min})$, the left anterior descending coronary artery was completely occluded by the method described by Lubbe et al. (13), beneath the left auricular appendage together with the adjacent veins. The ligature was released after $15 \mathrm{~min}$ and reperfusion was performed for an additional $30 \mathrm{~min}$. Cardiac arrhythmias were defined as the presence of ventricular tachycardia and/ or ventricular fibrillation after the ligature of the coronary artery was released. To obtain a quantitative measurement, the arrhythmias were graded arbitrarily by their duration, with the duration of 30 min considered to be irreversible arrhythmias. Therefore, the occurrence of cardiac arrhythmias for 0 to $3 \mathrm{~min}$ was assigned a factor of 2; 3 to 6 min was assigned a factor of $4 ; 6$ to $10 \mathrm{~min}$ was assigned a factor of $6 ; 10$ to $15 \mathrm{~min}$ was assigned a factor of $8 ; 15$ to 20 min was assigned a factor of 10; 20 to 25 min was assigned a factor of 11 , and 25 to 30 min was assigned a factor of 12 . A value of 0 to 12 was thus obtained in each experiment and was denoted as arrhythmia severity index (ASI) (14).

\section{Statistical analysis}

Data are reported as mean \pm SEM. Statistical analysis was performed by the Student $t$-test or one- or two-way ANOVA followed by the Bonferroni test. $P<0.05$ was considered to be significant (GraphPad Prism 4.0, USA).

\section{Results}

As depicted in Figure 1, ventricular tachycardia and/or ventricular fibrillation were observed in young and middleaged groups during the reperfusion period. However, the 
duration of $\mathrm{I} / \mathrm{R}$ arrhythmias was significantly longer in young rats compared to middle-aged rats (ASI: $9.4 \pm 1.0$ vs $3.0 \pm 0.3$ arbitrary units in young and middle-aged rats, respectively; Figure $2 \mathrm{~A}$ ). In addition, $50 \%$ of the hearts from

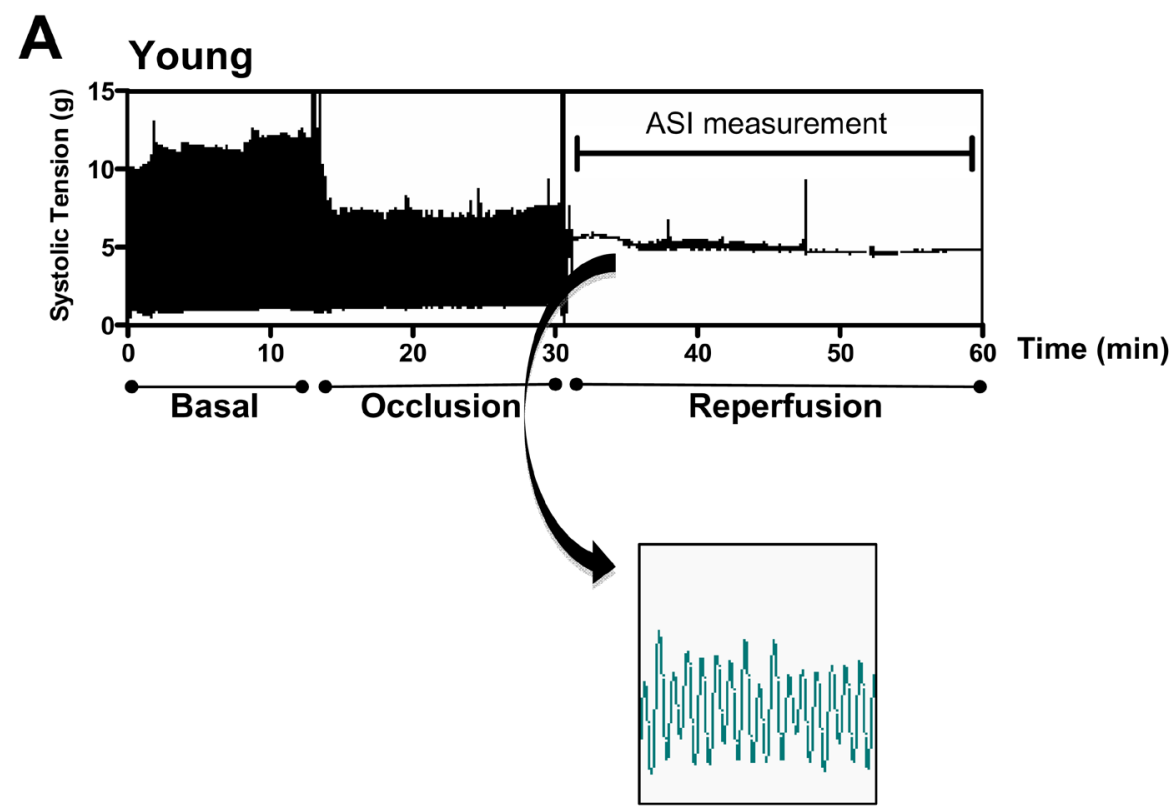

Ventricular fibrillation

\section{B Middle-aged}

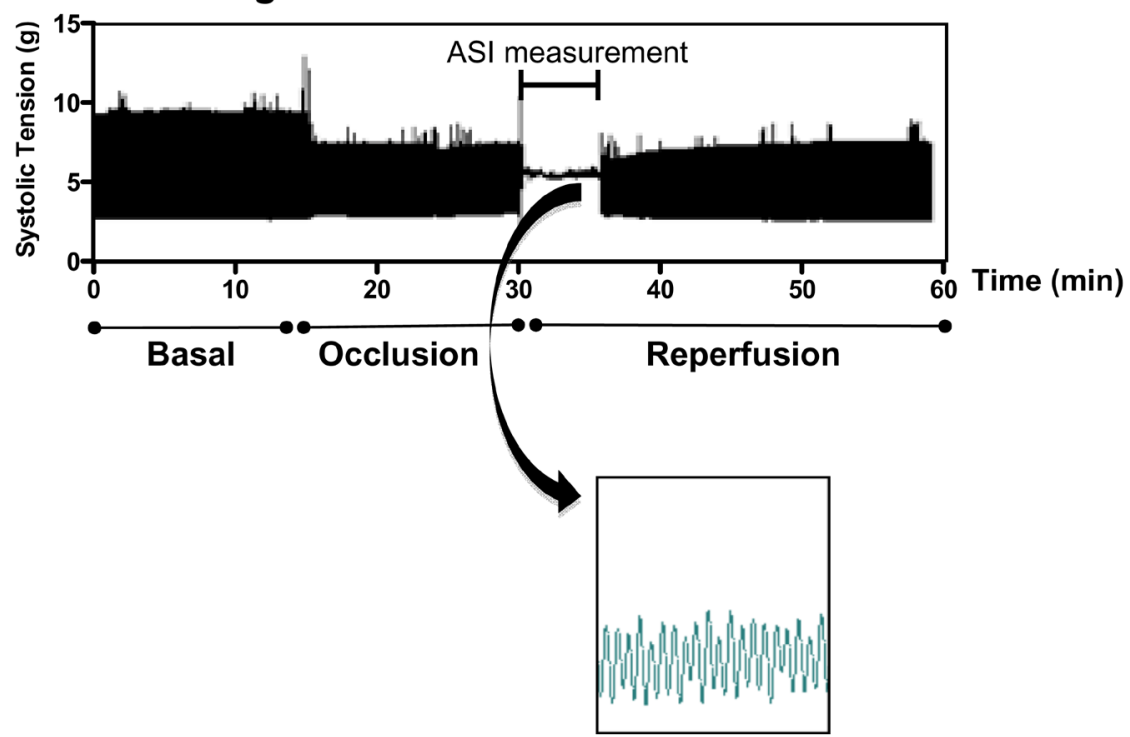

Ventricular fibrillation

Figure 1. Original raw traces of contraction force (tension, g) of representative experiments conducted on $(A)$ young and $(B)$ middle-aged rats. Arrhythmias were produced by 15 -min occlusion of the left anterior descending coronary artery in isolated rat hearts followed by reperfusion for $30 \mathrm{~min}$. Insets demonstrate ventricular fibrillation during the reperfusion period. Arrhythmia severity index $(\mathrm{ASI})=12$ for the young rat and $\mathrm{ASI}=4$ for the middle-aged rat. 
young rats presented irreversible arrhythmias while none of the hearts from middle-aged animals showed irreversible arrhythmias during the reperfusion period. Thus, the incidence of irreversible arrhythmias was markedly higher in young rats compared to older rats (Figure 2B).

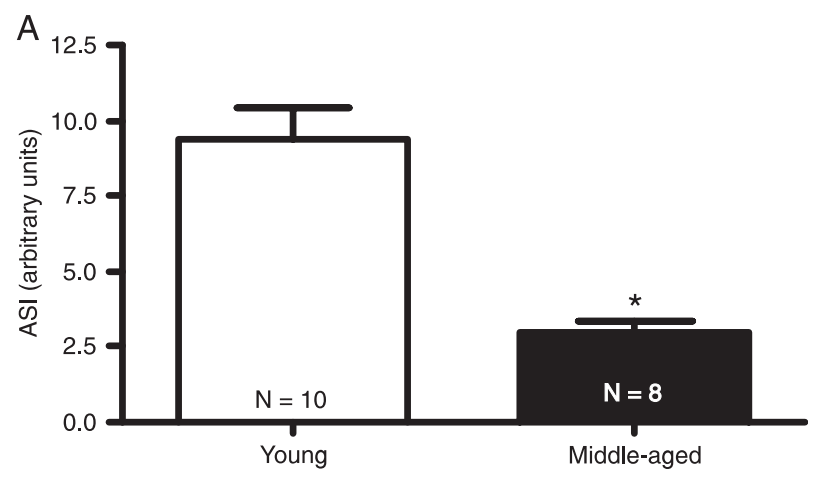

B

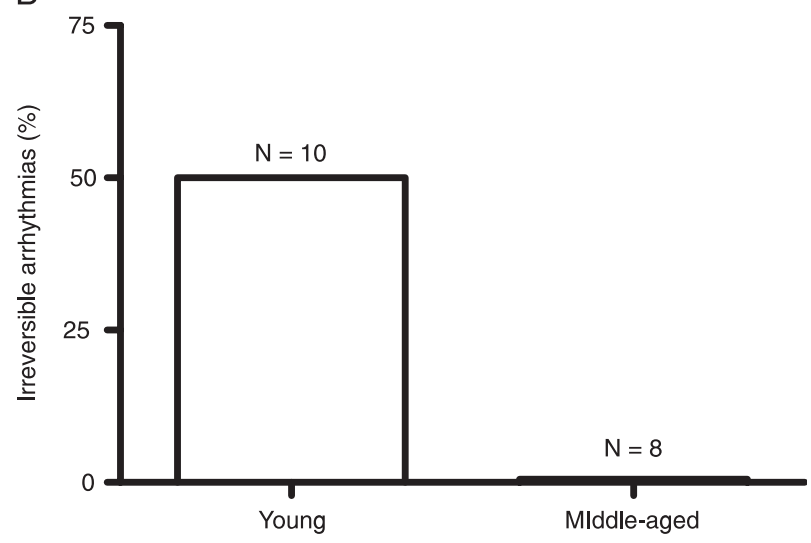

Figure 2. Effect of age on ischemia/reperfusion arrhythmias in female rats. Arrhythmias were produced by 15 -min occlusion of the left anterior descending coronary artery in isolated rat hearts followed by reperfusion. $A$, Averaged arrhythmia severity index (ASI) and $B$, percentage of irreversible arrhythmias. $\mathrm{N}=8-10$ rats. ${ }^{*} \mathrm{P}<0.05$ vs young group (Student $t$-test).

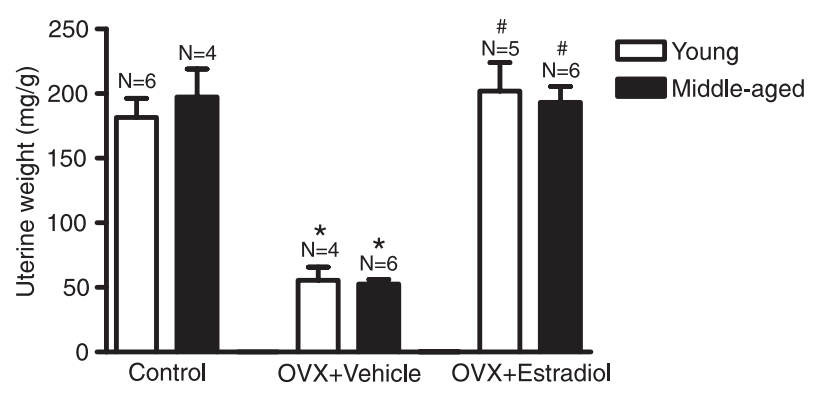

Figure 3. Effects of ovariectomy (OVX) and hormonal treatment (estradiol) on uterine weight. Uterine weight is reported as the ratio between uterine weight $(\mathrm{mg})$ and body weight $(\mathrm{g}) . \mathrm{N}=4-6$ rats. ${ }^{*} \mathrm{P}<0.05$ vs control of the same age, ${ }^{\#} \mathrm{P}<0.05$ vs vehicletreated group of the same age (two-way ANOVA followed by the Bonferroni test).
The success of the OVX procedure and of $E_{2}$ treatment was confirmed by the analysis of uterine weight. OVX caused a significant reduction of the uterine weight of both young and middle-aged rats, which was reversed by 4-day $E_{2}$ administration (Figure 3). No significant changes in body weight were observed when comparing the young groups (control: 179.8 $\pm 4.8 \mathrm{~g}$; vehicle: $173.8 \pm 4.9 \mathrm{~g}$; $\mathrm{E}_{2}: 172.0 \pm 6.8 \mathrm{~g}$ ) or when comparing the middle-aged groups (control: $351.4 \pm 15.8 \mathrm{~g}$; vehicle: $332.0 \pm 13.3 \mathrm{~g}$; $\mathrm{E}_{2}: 356.4 \pm 12.8 \mathrm{~g}$ ).

We next determined if short-term administration of $E_{2}$ might modify the duration and incidence of I/R arrhythmias in young and middle-aged rats. Short-term $\mathrm{E}_{2}$ administration induced a significant reduction in the rhythm disturbances of young rats (ASI: $6.6 \pm 1.7$ in vehicle group vs $3.8 \pm 0.8$ in $E_{2}$ group; Figure $4 A$ ). On the other hand, treatment with $E_{2}$ did not cause any significant effect on the duration of I/R arrhythmias in middle-aged rats (Figure 4B).

In terms of cardiac function, control and ovariectomized $\mathrm{E}_{2}$-treated middle-aged rats presented lower coronary flow
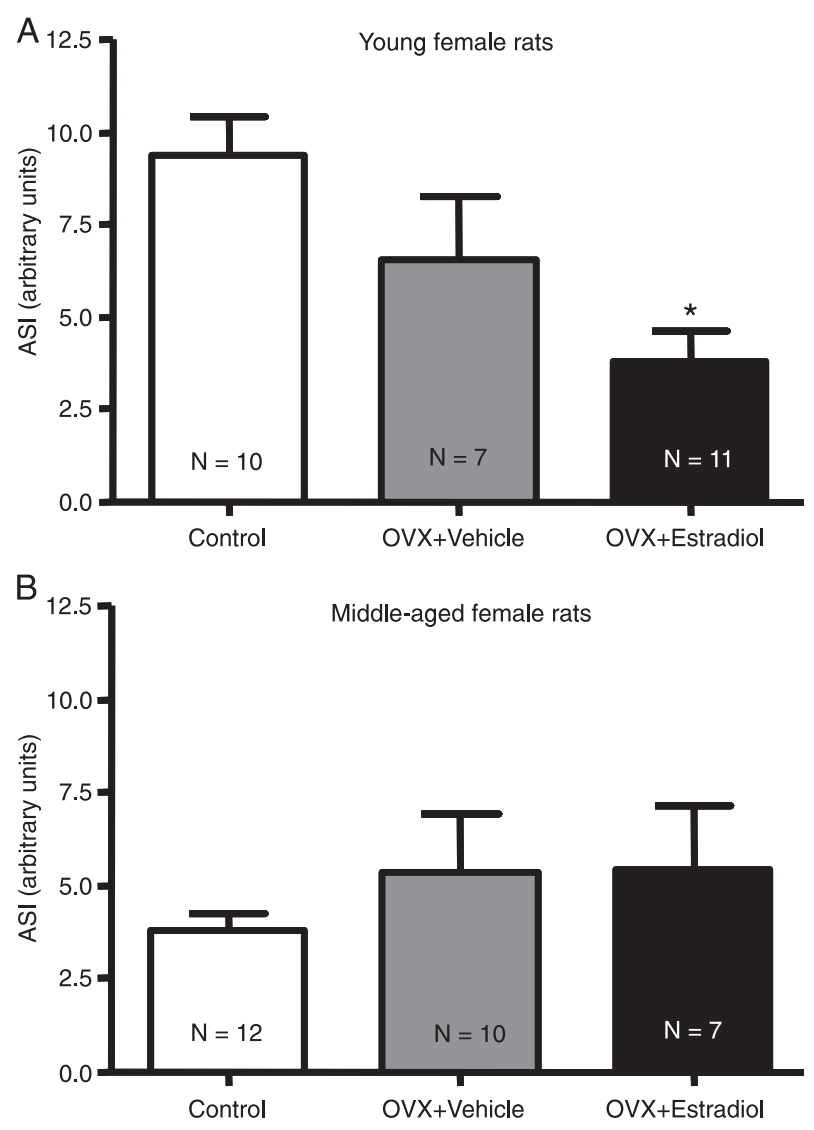

Figure 4. Effects of estradiol on ischemia/reperfusion arrhythmias in isolated hearts from $(A)$ young and $(B)$ middle-aged female rats. Arrhythmias were produced by 15 -min occlusion of the left anterior descending coronary artery in isolated rat hearts followed by reperfusion. $\mathrm{ASI}=$ arrhythmia severity index; OVX = ovariectomy. $\mathrm{N}=7-12$ rats. ${ }^{*} \mathrm{P}<0.05$ vs control group (one-way ANOVA followed by the Bonferroni test). 
compared to young rats. In ovariectomized $\mathrm{E}_{2}$-untreated rats no significant differences were observed between young and middle-aged animals (Figure $5 \mathrm{~A}$ ). The systolic tension was lower in control and in ovariectomized $\mathrm{E}_{2}$-untreated and -treated middle-aged animals compared to young rats. However, systolic tension was significantly higher in vehicle-treated rats than in control middle-aged animals (Figure $5 B$ ). No significant differences in diastolic tension were observed in any of the groups (Figure $5 \mathrm{C}$ ). Heart rate was lower only in control middleaged animals compared to young rats. In OVX-untreated and OVX + $\mathrm{E}_{2}$-treated rats, no significant differences were observed between young and middle-aged animals. However, the heart rate of young $E_{2}$-treated rats was significantly lower than that of young control animals (Figure $5 \mathrm{D}$ ). In addition, $\mathrm{E}_{2}$ administration induced a significant increase in QT and PR intervals in young rats compared to control. No significant changes in QT or PR intervals were observed in middle-aged $\mathrm{E}_{2}$-treated rats (Table 1).

Table 1. Effects of estradiol on PR and QT intervals of hearts isolated from young and middle-aged female rats during the basal period.

\begin{tabular}{|c|c|c|c|c|}
\hline & \multicolumn{2}{|c|}{ Young rats (6-7 weeks old) } & \multicolumn{2}{|c|}{ Middle-aged rats (12-14 months old) } \\
\hline & $\mathrm{PR}(\mathrm{ms})$ & QT (ms) & $\mathrm{PR}(\mathrm{ms})$ & QT (ms) \\
\hline Control & $33.15 \pm 1.41$ & $75.95 \pm 2.37$ & $37.76 \pm 0.52$ & $79.10 \pm 3.55$ \\
\hline$O V X+V e h$ & $34.74 \pm 1.82$ & $70.51 \pm 4.56$ & $36.53 \pm 2.06$ & $73.91 \pm 2.91$ \\
\hline $\mathrm{OVX}+\mathrm{E}_{2}$ & $39.67 \pm 1.87^{+}$ & $87.65 \pm 3.12^{+*}$ & $37.32 \pm 2.20$ & $77.05 \pm 1.74$ \\
\hline
\end{tabular}

Data are reported as mean \pm SEM for 5-7 animals/group. $\mathrm{ms}=$ millisecond; OVX = ovariectomy; $E_{2}=$ estradiol. ${ }^{+} \mathrm{P}<0.05$ vs control at the same age; ${ }^{*} \mathrm{P}<0.05$ vs vehicle (Veh) at the same age (one-way ANOVA followed by the Bonferroni test).
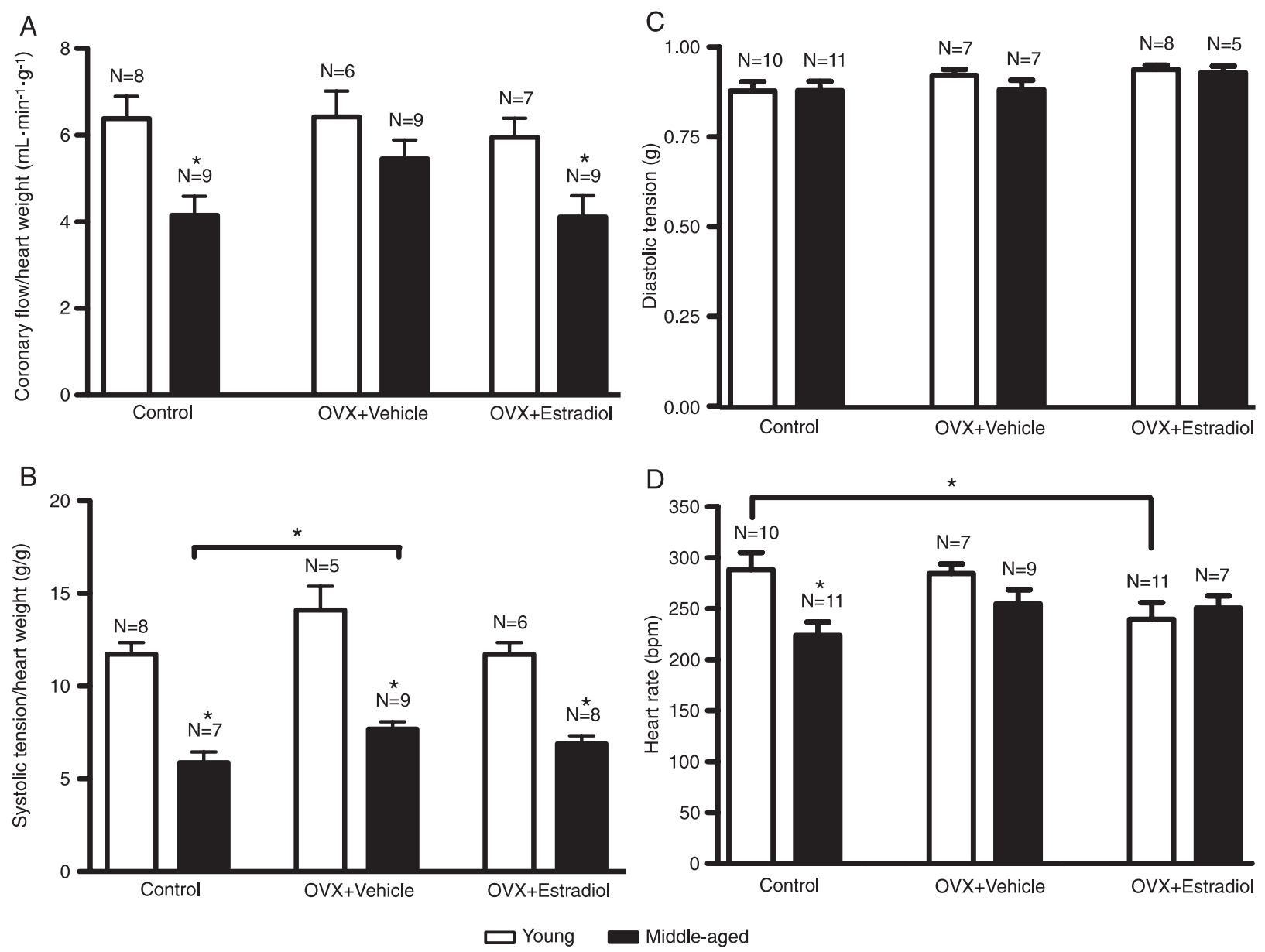

Figure 5. Effects of estradiol on coronary flow $(A)$, systolic tension $(B)$, diastolic tension $(C)$, and heart rate $(D)$ of isolated perfused hearts from young and middle-aged female rats during the basal period. OVX = ovariectomy. $N=5-11$ rats. ${ }^{*} P<0.05$ (two-way ANOVA followed by the Bonferroni test). 


\section{Discussion}

The results obtained in this study show that $E_{2}$ treatment was less effective in attenuating cardiac reperfusion arrhythmias in middle-aged female rats compared to young female rats, thereby suggesting that the protective effects of estrogen on I/R insults are age-dependent. One possible explanation for this observation is that aging influences the cellular regulation of cardiac estrogen receptors (ERs). The cardiac effects of $E_{2}$ are mediated, at least in part, by two distinct receptors: ER-alpha and ER-beta (15-17). Vornehm et al. (18) found that both ER-alpha and ER-beta are involved in mediating $\mathrm{E}_{2}$-induced rapid cardioprotection after I/R injury. Additionally, a membrane-bound G proteincoupled estrogen receptor (GPER) with high affinity for estrogen has been identified in the heart $(19,20)$. Activation of GPER improves the functional recovery and reduces the infarct size in isolated rat hearts following $\mathrm{I} / \mathrm{R}$ through a PI3K-dependent and gender-independent mechanism (21). Although we did not evaluate cardiac ER expression in the current study, Jazbutyte et al. (22) demonstrated that ER-alpha expression in hearts was significantly lower in sham-operated and in ovariectomized senescent (24 months old) SHR compared to young animals ( 3 months old). On the other hand, the expression of ER-beta was detected at comparable levels in hearts of young and senescent rats. Taken together, these findings suggest that cardiac ER expression decreases with age and may influence the responses to $E_{2}$ treatment. Consequently, this leads to a reduction in the cardioprotective effects of $E_{2}$.

One may argue that 4-day $\mathrm{E}_{2}$ treatment could not be sufficient to modulate the cardiovascular system. However, as shown by Belo et al. (12), short-term $\mathrm{E}_{2}$ administration resulted in intense reduction of SHR blood pressure with a concomitant increase in the synthesis and release of atrial natriuretic peptide, which is mainly synthesized, stored and secreted by cardiac atria (23). Also, many studies have demonstrated the effects of estrogen infusion on cardiac activity in rats $(5,24)$. We found that the efficiency of shortterm $E_{2}$ treatment was demonstrated by the increase in uterine weight observed in ovariectomized $E_{2}$-treated young and middle-aged rats. These latter data suggest that estrogen metabolism is similar in young and middle-aged rats, thereby indicating that aging did not interfere with the metabolism of $E_{2}$.

In keeping with previous reports, we observed that, in addition to the antiarrhythmogenic effect induced by estrogen treatment, young animals had an increased QT interval. Indeed, Burke et al. (25) have reported that the QT interval tends to be longer in women than in men. Also, Philp et al. (5) have shown that $E_{2}$ induces a blockade of $\mathrm{Ca}^{2+}$ channels in female rats. $\mathrm{Ca}^{2+}$ channel blockers possess antiarrhythmogenic actions in animal models of myocardial ischemia (26) and may contribute to the longer QT interval observed in females (27). Additionally, the $\mathrm{I}_{\mathrm{CaL}}$ transmural gradient together with lower $I_{\mathrm{K}}$ and $I_{\mathrm{K} 1}$ densities in female than in male rabbit ventricles (28) could result in prolonged repolarization and greater transmural dispersion of repolarization (27). Thus, our findings suggest that prolongation of the QT interval might be involved in the antiarrhythmogenic effects observed in ovariectomized young rats treated with estrogen.

Although there is evidence that $\mathrm{E}_{2}$ can contribute to the reduction of arrhythmias as a consequence of vasorelaxation $(29,30)$, in our study this possibility is an unlikely mechanism since $\mathrm{E}_{2}$-treated rats presented no alterations in coronary flow.

Also, it is important to note that, although we did not measure the plasma $E_{2}$ levels of the animals, Belo et al. (12) demonstrated that treatment with $\mathrm{E}_{2}$ for 4 days induces a sustained increase in plasma $E_{2}$ levels, reaching $40-50$ pg/ $\mathrm{mL}$. These levels are higher than the plasma concentration of $E_{2}$ in female control rats, whose values range between 5 and $40 \mathrm{pg} / \mathrm{mL}$ during the estrous cycle $(12,31)$. It is likely that estrogen levels were higher in the $\mathrm{OVX}+\mathrm{E}_{2}$-treated group compared to both the OVX + vehicle and the intact control group. Thus, estrogen treatment producing blood concentrations exceeding endogenous levels might be required to reduce $\mathrm{ASI}$ in young animals.

The current study demonstrated that short-term $\mathrm{E}_{2}$ treatment protects against I/R arrhythmias in hearts of young females rats, but not of middle-aged rats, thereby indicating that the anti-arrhythmogenic effect of $E_{2}$ is dependent on age. This cardioprotective effect might be related to a lengthening of the QT interval. However, further experiments are needed to clearly identify the mechanisms underlying the anti-arrhythmogenic effects of aging and of $E_{2}$ in young female rats.

\section{Acknowledgments}

We are grateful to Elisabeth Bontempo and Janine Costa Ivo for helpful technical assistance. Research supported by FAPEMIG, CNPq, and CAPES.

\section{References}

1. Wenger NK. Clinical characteristics of coronary heart disease in women: emphasis on gender differences. Cardiovasc $\operatorname{Res} 2002$; 53: 558-567.

2. Rosano GM, Simon T, Mercuro G, Sans S, Schenck-Gustaff- son $\mathrm{K}$, Stevenson JC, et al. Hormone replacement therapy: where we stand in Europe. Eur Heart $J$ 2001; 22: 439-441.

3. Wang Y, Wang Q, Zhao Y, Gong D, Wang D, Li C, et al. Protective effects of estrogen against reperfusion arrhythmias 
following severe myocardial ischemia in rats. Circ J 2010; 74: 634-643.

4. Patten RD, Pourati I, Aronovitz MJ, Baur J, Celestin F, Chen $\mathrm{X}$, et al. 17Beta-estradiol reduces cardiomyocyte apoptosis in vivo and in vitro via activation of phospho-inositide-3 kinase/Akt signaling. Circ Res 2004; 95: 692-699.

5. Philp KL, Hussain M, Byrne NF, Diver MJ, Hart G, Coker SJ. Greater antiarrhythmic activity of acute 17beta-estradiol in female than male anaesthetized rats: correlation with $\mathrm{Ca}^{2+}$ channel blockade. Br J Pharmacol 2006; 149: 233-242.

6. Wang M, Tsai BM, Reiger KM, Brown JW, Meldrum DR. 17-Beta-estradiol decreases p38 MAPK-mediated myocardial inflammation and dysfunction following acute ischemia. J Mol Cell Cardiol 2006; 40: 205-212.

7. Hulley S, Grady D, Bush T, Furberg C, Herrington D, Riggs $\mathrm{B}$, et al. Randomized trial of estrogen plus progestin for secondary prevention of coronary heart disease in postmenopausal women. Heart and Estrogen/Progestin Replacement Study (HERS) Research Group. JAMA 1998; 280: 605-613.

8. Grady D, Herrington D, Bittner V, Blumenthal R, Davidson $M$, Hlatky M, et al. Cardiovascular disease outcomes during 6.8 years of hormone therapy: Heart and Estrogen/Progestin Replacement Study follow-up (HERS II). JAMA 2002; 288: 49-57.

9. Hulley S, Furberg C, Barrett-Connor E, Cauley J, Grady D, Haskell W, et al. Noncardiovascular disease outcomes during 6.8 years of hormone therapy: Heart and Estrogen/ Progestin Replacement Study follow-up (HERS II). JAMA 2002; 288: 58-66.

10. Rossouw JE, Anderson GL, Prentice RL, LaCroix AZ, Kooperberg C, Stefanick ML, et al. Risks and benefits of estrogen plus progestin in healthy postmenopausal women: principal results from the Women's Health Initiative randomized controlled trial. JAMA 2002; 288: 321-333.

11. Anderson GL, Limacher M, Assaf AR, Bassford T, Beresford $\mathrm{SA}$, Black $\mathrm{H}$, et al. Effects of conjugated equine estrogen in postmenopausal women with hysterectomy: the Women's Health Initiative randomized controlled trial. JAMA 2004; 291: 1701-1712.

12. Belo NO, Silva-Barra J, Carnio EC, Antunes-Rodrigues J, Gutkowska J, Dos Reis AM. Involvement of atrial natriuretic peptide in blood pressure reduction induced by estradiol in spontaneously hypertensive rats. Regul Pept 2004; 117: 53-60.

13. Lubbe WF, Daries PS, Opie LH. Ventricular arrhythmias associated with coronary artery occlusion and reperfusion in the isolated perfused rat heart: a model for assessment of antifibrillatory action of antiarrhythmic agents. Cardiovasc Res 1978; 12: 212-220.

14. Ferreira AJ, Santos RA, Almeida AP. Angiotensin-(1-7): cardioprotective effect in myocardial ischemia/reperfusion. Hypertension 2001; 38: 665-668.

15. Grohe C, Kahlert S, Lobbert K, Stimpel M, Karas RH, Vetter $\mathrm{H}$, et al. Cardiac myocytes and fibroblasts contain functional estrogen receptors. FEBS Lett 1997; 416: 107-112.

16. Taylor AH, Al-Azzawi F. Immunolocalisation of oestrogen receptor beta in human tissues. $J$ Mol Endocrinol 2000; 24: 145-155.

17. Mendelsohn ME, Karas RH. Molecular and cellular basis of cardiovascular gender differences. Science 2005; 308: 1583-1587.

18. Vornehm ND, Wang M, Abarbanell A, Herrmann J, Weil B, Tan J, et al. Acute postischemic treatment with estrogen receptor-alpha agonist or estrogen receptor-beta agonist improves myocardial recovery. Surgery 2009; 146: 145-154.

19. Filardo EJ, Quinn JA, Frackelton AR Jr, Bland KI. Estrogen action via the $G$ protein-coupled receptor, GPR30: stimulation of adenylyl cyclase and CAMP-mediated attenuation of the epidermal growth factor receptor-to-MAPK signaling axis. Mol Endocrinol 2002; 16: 70-84.

20. Thomas P, Pang Y, Filardo EJ, Dong J. Identity of an estrogen membrane receptor coupled to a $G$ protein in human breast cancer cells. Endocrinology 2005; 146: 624-632.

21. Deschamps AM, Murphy E. Activation of a novel estrogen receptor, GPER, is cardioprotective in male and female rats. Am J Physiol Heart Circ Physiol 2009; 297: H1806-H1813.

22. Jazbutyte V, Hu K, Kruchten P, Bey E, Maier SK, Fritzemeier $\mathrm{KH}$, et al. Aging reduces the efficacy of estrogen substitution to attenuate cardiac hypertrophy in female spontaneously hypertensive rats. Hypertension 2006; 48: 579-586.

23. Lang RE, Tholken H, Ganten D, Luft FC, Ruskoaho H, Unger T. Atrial natriuretic factor - a circulating hormone stimulated by volume loading. Nature 1985; 314: 264-266.

24. Li J, Xiao J, Liu Y, Zhang G, Zhang H, Liang D, et al. Mitochondrial benzodiazepine receptors mediate cardioprotection of estrogen against ischemic ventricular fibrillation. Pharmacol Res 2009; 60: 61-67.

25. Burke JH, Ehlert FA, Kruse JT, Parker MA, Goldberger JJ, Kadish AH. Gender-specific differences in the QT interval and the effect of autonomic tone and menstrual cycle in healthy adults. Am J Cardiol 1997; 79: 178-181.

26. Curtis MJ, Walker MJ. The mechanism of action of calcium antagonists on arrhythmias in early myocardial ischaemia: studies with nifedipine and DHM9. Br J Pharmacol 1988; 94: 1275-1286.

27. Pham TV, Robinson RB, Danilo P Jr, Rosen MR. Effects of gonadal steroids on gender-related differences in transmural dispersion of L-type calcium current. Cardiovasc Res 2002; 53: 752-762.

28. Liu XK, Katchman A, Drici MD, Ebert SN, Ducic I, Morad M, et al. Gender difference in the cycle length-dependent QT and potassium currents in rabbits. J Pharmacol Exp Ther 1998; 285: 672-679.

29. Kitazawa T, Hamada E, Kitazawa K, Gaznabi AK. Nongenomic mechanism of 17 beta-oestradiol-induced inhibition of contraction in mammalian vascular smooth muscle. $J$ Physiol 1997; 499 (Part 2): 497-511.

30. Santos RL, Abreu GR, Bissoli NS, Moyses MR. Endothelial mediators of 17 beta-estradiol-induced coronary vasodilation in the isolated rat heart. Braz J Med Biol Res 2004; 37: 569-575.

31. Neill JD. Knobil and Neill's physiology of reproduction. 3rd edn. Amsterdam: Elsevier; 2006. 